Resenhas 



\section{Um novo olhar para uma metáfora clássica}

Marcos Paulo da Silva*

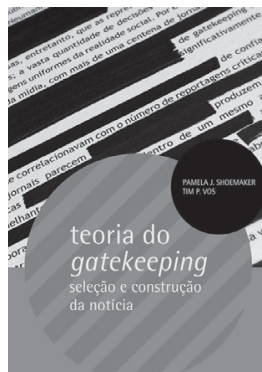

SHOEMAKER, Pamela J., VOS, Tim P. Teoria do gatekeeping: seleção e construção da notícia. Porto Alegre: Editora Penso, 2011. 216p.

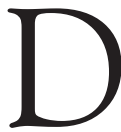

evido ao acentuado crescimento das tecnologias digitais a partir do final do século 20, e especialmente após o importante impacto que os usuários online passam a desempenhar na arena pública (a primeira eleição presidencial de Barack Obama nos Estados Unidos constitui um marco significativo desse processo), são muitas as vozes ao redor do globo a anunciar a morte inevitável da clássica Teoria do Gatekeeping. A alegação apresenta-se sedutora posto que o advento da "informação em rede" coloca em posição de xeque o tradicional pressuposto de que "os eventos que não são cobertos pela mídia ficam ausentes da visão de mundo do público" (desde que, evidentemente, a audiência não tenha uma experiência pessoal com o próprio evento) - ideia que por décadas serve de suporte para diferentes abordagens teóricas na pesquisa comunicacional.

* Doutor em Comunicação Social pelo Programa de Pós-Graduação da Universidade Metodista de São Paulo (UMESP). São Bernardo do Campo-SP, Brasil.E-mail: silva_mp@uol.com.br 
É justamente nesse contexto, como espécie de resposta crítica a tal "certificado de óbito", que desponta no horizonte acadêmico o livro "Teoria do Gatekeeping: seleção e construção da notícia”, de Pamela J. Shoemaker (responsável pela Cátedra John Ben Snow da Syracuse University) e Tim P. Vos (professor da University of Missouri). A obra, recentemente, recebeu uma versão em português publicada pela editora brasileira Penso (tradução de Vivian Nickel e supervisão de Marcia Benneti). Nela, os autores lançam mão de uma interessante argumentação ao reconhecerem que o seminal modelo teórico criado nos anos 1940 pelo psicólogo norte-americano Kurt Lewin pode ser ainda útil - com suas devidas atualizações - para o entendimento do que eles denominam de "gatekeeping do século XXI".

$\mathrm{Na}$ primeira parte, os autores apresentam uma visão geral da tradicional teoria de Kurt Lewin que uma década mais tarde (no início dos anos 1950) passa a ser aplicada por David White ao estudo das notícias. A ideia de Lewin de utilizar as metáforas de "gates" e "gatekeepers" (literalmente "portões" e "porteiros" em inglês) é originalmente aplicada em um estudo sobre hábitos alimentares de famílias norte-americanas no período pós-Primeira Guerra Mundial. Essa simples metáfora ganha corpo no campo da Comunicação a partir do momento em que White, um ex- assistente de pesquisa de Lewin, decide adaptar o modelo para analisar o processo de seleção do conteúdo noticioso. Munidos de um levantamento histórico dessa conjuntura, Shoemaker e Vos elucidam o desenvolvimento dos conceitos relacionados ao processo de gatekeeping, bem como os novos modelos aprimorados por diferentes pesquisadores nas décadas seguintes.

A segunda parte da obra, denominada "Níveis de análise", apresenta uma interessante contribuição teórico-metodológica aos estudos sobre a seleção noticiosa. Baseados em estrutura semelhante àquela inicialmente utilizada por Pamela Shoemaker no livro "Mediating the message: theories of influences on mass media content", de 1996, os autores explicitam cinco níveis de análise nos quais as reflexões sobre o processo de gatekeeping (e sobre o jornalismo em geral) podem se focar. Tais níveis variam das ca- 
racterísticas individuais dos jornalistas às mais amplas estruturas socioculturais (a exemplo da cultura e da ideologia), passando pelas rotinas jornalísticas e pelos tensionamentos intrínsecos ao terreno organizacional.

Ao menos dois parênteses merecem ser destacados neste ponto. Em primeiro lugar, o nível mais amplo de análise (chamado pelos autores de "sistema social"), seja ele entendido como cultura ou como ideologia, deve ser também enfatizado como um pano de fundo que permeia cada um dos outros níveis apresentados (uma vez que é teoricamente mais complexo). Na sequência, as rotinas jornalísticas devem ser sublinhadas pelo fato de representarem um nível emblemático de análise no qual diferentes características individuais e tensionamentos organizacionais (incluindo regras implícitas e pressões do mercado) cruzam-se em trocas simbólicas para a definição sobre o que deve e o que não deve ser considerado notícia.

Finalmente, Shoemaker e Vos dedicam a terceira parte do livro para apresentar uma nova perspectiva para a "Teoria do Gatekeeping" (focada, como definem, nas mudanças introduzidas pelas novas tecnologias digitais). Para tanto, os autores aprofundam a ideia de "campo" e incorporam brevemente ao debate iniciado por Kurt Lewin nos anos 1940 a abordagem crítica de Pierre Bourdieu. Em seguida, um modelo gráfico atualizado é apresentado aos leitores com a finalidade de reinterpretar o processo clássico do gatekeeping - isto é, da seleção propriamente dita do conteúdo noticioso. É neste momento que, ao lado de "Níveis de análise" anteriormente apresentado, se localiza a outra grande contribuição teórica do livro: a inclusão de um novo canal - a audiência - no processo de seleção e de construção das notícias. Apesar de a obra ter sido originalmente publicada em 2009 nos Estados Unidos, os autores já consideram algumas das mais recentes mudanças no campo jornalístico motivadas pelos novos recursos e ferramentas da Internet. Como forma de ilustrar empiricamente essa nova abordagem, eles lançam mão de um estudo encabeçado pela própria Pamela Shoemaker sobre o modo como as notícias mais comentadas e encaminhadas via e-mail pelos leitores do The New York Times têm influenciado a dinâmica de seleção do conteúdo noticioso do veículo. 
Provavelmente, alguns dos pontos mais polêmicos do livro estão relacionados à linguagem por vezes utilizada para se referir a abordagens teóricas e métodos de análise. Muitos conceitos citados estão atrelados a estudos quantitativos e a hipóteses estatisticamente verificáveis, procedimentos mais comuns na pesquisa em Comunicação nos Estados Unidos do que no Brasil. Além disso, como as mudanças tecnológicas são rápidas e continuam em curso, os autores recomendam uma lista de desafios futuros - sobretudo no terreno metodológico - para as relações entre as novas tecnologias e a seleção noticiosa. Assim, acaba por se fazer valer a pena a leitura do livro - especialmente para estudantes e pesquisadores preocupados com as recentes dinâmicas jornalísticas ou para aqueles que, precocemente, já assinaram o "certificado de óbito" dessa clássica e interessante metáfora. 